\title{
Prospecção de minerais pesados em placeres no litoral Sul do Rio Grande do Norte (RN): método aeroradiométrico e concentrado de bateia
}

Matheus Dias Oliveira ${ }^{1 *}$, Asmminey Ariane da Silva Nascimento ${ }^{1}$, Vanildo Fonseca Pereira ${ }^{1}$ e Alexandre Magno Rocha da Rocha ${ }^{2},{ }^{1}$ Universidade Federal do Rio Grande do Norte (UFRN), ${ }^{2}$ Instituto Federal de Educação, Ciência e Tecnologia do Rio Grande do Norte (IFRN).

Copyright 2019, SBGf - Sociedade Brasileira de Geofísica

This paper was prepared for presentation during the $16^{\text {th }}$ International Congress of the Brazilian Geophysical Society held in Rio de Janeiro, Brazil, 19-22 August 2019.

Contents of this paper were reviewed by the Technical Committee of the $16^{\text {th }}$ International Congress of the Brazilian Geophysical Society and do not necessarily represent any position of the SBGf, its officers or members. Electronic reproduction or storage of any part of this paper for commercial purposes without the written consent of the Brazilian Geophysical Society is prohibited.

\section{Abstract}

Data from aero radiometric surveys and gold pans concentrates were interpreted to locate prospective regions of heavy minerals in placer deposits on the southern coast of Rio Grande do Norte, Brazil. The processing of the data allowed the individual analysis of the thorium (eTh) and uranium (eU) channels. Thus the identification of the anomalies related to the thorium and uranium elements became evident within the study area in the river basins of the Trairí, Jacú, Catú and Curimataú rivers. The anomalies of these channels can be associated to the stable minerals of these elements, monazite and zircon, their concentrations are distributed semi-homogeneously in the study area, highlighting the southern portion with high concentrations of $U$ and Th and can refer to zircon-monazitic placers. Thus, the effectiveness of the geophysical method in the location of zircon-monazithic pleasure deposits is suggested.

\section{Introdução}

Minerais pesados se destacam em meio aos sedimentos inconsolidados, apresentando densidades superiores a $2,9 \mathrm{~g} / \mathrm{cm}^{3}$ em comparação o quartzo e os feldspatos, que possuem densidades aproximadas de $2,65 \mathrm{~g} / \mathrm{cm}^{3}$. Sua deposição é favorável em depósitos sedimentares do tipo "placer" (Addad, 2010). A partir de dados disponibilizados pela Companhia de Pesquisa de Recursos Minerais (CPRM) de concentrado de bateia, foram selecionados minerais pesados economicamente relevantes para a indústria. Dentre estes estão: cianita, ilmenita, magnetita, monazita, rutilo e zircão. A amostragem geoquímica englobou as bacias hidrográficas dos rios Catú, Curimataú, Jacú e Trairí, localizadas no litoral sul do estado do Rio Grande do Norte. A mesma ocorreu em locais com diminuições bruscas na velocidade da corrente destas drenagens, onde é favorecida a deposição de minerais densos (Oliva, 1985).

De acordo com Dickson e Scott (1997) o elemento potássio $(K)$ possui maior abundância na crosta $(2,35 \%)$ em relação aos elementos urânio (U) com $\sim 3$ ppm e tório (Th) com 12 ppm, os quais possuem suas radiações capadas pelo método. Considerando esse fator, suas distribuições estão atreladas a lixiviação de rochas banhadas pelas drenagens locais e em relação a suas mobilidades, Boyle (1982) ressalta o elemento U apresenta uma maior vulnerabilidade. Em contrapartida, Souza (2005), associa a mobilidade do elemento Th a complexos solúveis de sulfatos, nitratos, carbonatos, fosfatos, silicatos, orgânicos e etc. Para melhor interpretação, foram excluídas as anomalias referentes ao potássio. Estas irão denotar a presença de minerais como: biotita, muscovita, k-feldspato e argilominerais, os quais não ocorrem em placeres. A maior entonação será nos elementos U e Th, de acordo com, Dickson e Scott (1997) suas anomalias estão relacionadas aos minerais de maior estabilidade: monazita e zircão. Finalmente, ao comparar os resultados, é esperada a inferência de anomalias que evidenciem possíveis regiões de concentração destes minerais, atingindo assim, a localidade dos depósitos sedimentares do tipo "placer" a partir da integração dos dados geoquímicos e dados do levantamento aeroradiométrico.

\section{Métodos}

Os dados geofísicos aerogamaespectrométricos são oriundos do projeto Borda Leste do Planalto da Borborema (1079), executado pela CPRM no ano de 2008, os quais foram processados no software Oasis Montaj, gerando assim os mapas de eTh e eU. A aquisição dos dados foi realizada pelo Exploranium GR820 acoplado a aeronaves, com linhas de voos na direção N-S, espaçamento de $500 \mathrm{~m}$ e $100 \mathrm{~m}$ de altura média do voo. Os dados geoquímicos de concentrado de bateia são referentes ao projeto Metalogênese das Províncias Minerais do Brasil (RN, PB, PE, $A L)$, executado pela CPRM até o ano de 2012. As drenagens foram incorporadas ao projeto a partir de dados disponíveis na Folha SB.24-Y-A-II (III) São José do Mipibu na escala de 1:100.000, executado pela CPRM em 2016, empregando o uso das drenagens das bacias hidrográficas que abrangem a área de estudo disponibilizados pelo projeto. Os dados mencionados estão disponíveis no website da Geobank http://geosgb.cprm.gov.br/.

Em seguida, procedeu-se com a confecção dos mapas dentro da plataforma ArcMap 10.5, possibilitando a confecção do mapa do Modelo Digital de Elevação (MDE) e relevo sombreado 1:100.000,baseando-se nos dados altimétricos digitais da missão SRTM (Shuttle Radar Topography Mission), obtidos no endereço https://earthexplorer.usgs.gov/. O Datum utilizado para georreferenciamento dos mapas foi o WGS 1984, Zona UTM 24S, seguindo dessa forma os dados obtidos pela CPRM. 


\section{Área de estudo}

A área de estudo encontra-se delimitada pela Folha SB.24-Y-A-II (III) São José do Mipibu e geograficamente entre as cidades de São José do Mipibu e Canguaretama, tendo como extremos os paralelos $06^{\circ} 00^{\prime \prime}$ e 06²4". O mapa MDE e relevo sombreado realçam as principais incisões fluviais presentes na área e destacam as feições de relevo, podendo assim ser identificados o entorno da laguna Guaraíras e incisões dos rios Trairí, Jacú, Catú e Curimataú (Fig. 1). As bacias hidrográficas localizadas na área foram usadas para a melhor observação das ocorrências dos minerais analisados, sendo sua distribuição mais concentrada próxima à foz das respectivas drenagens.

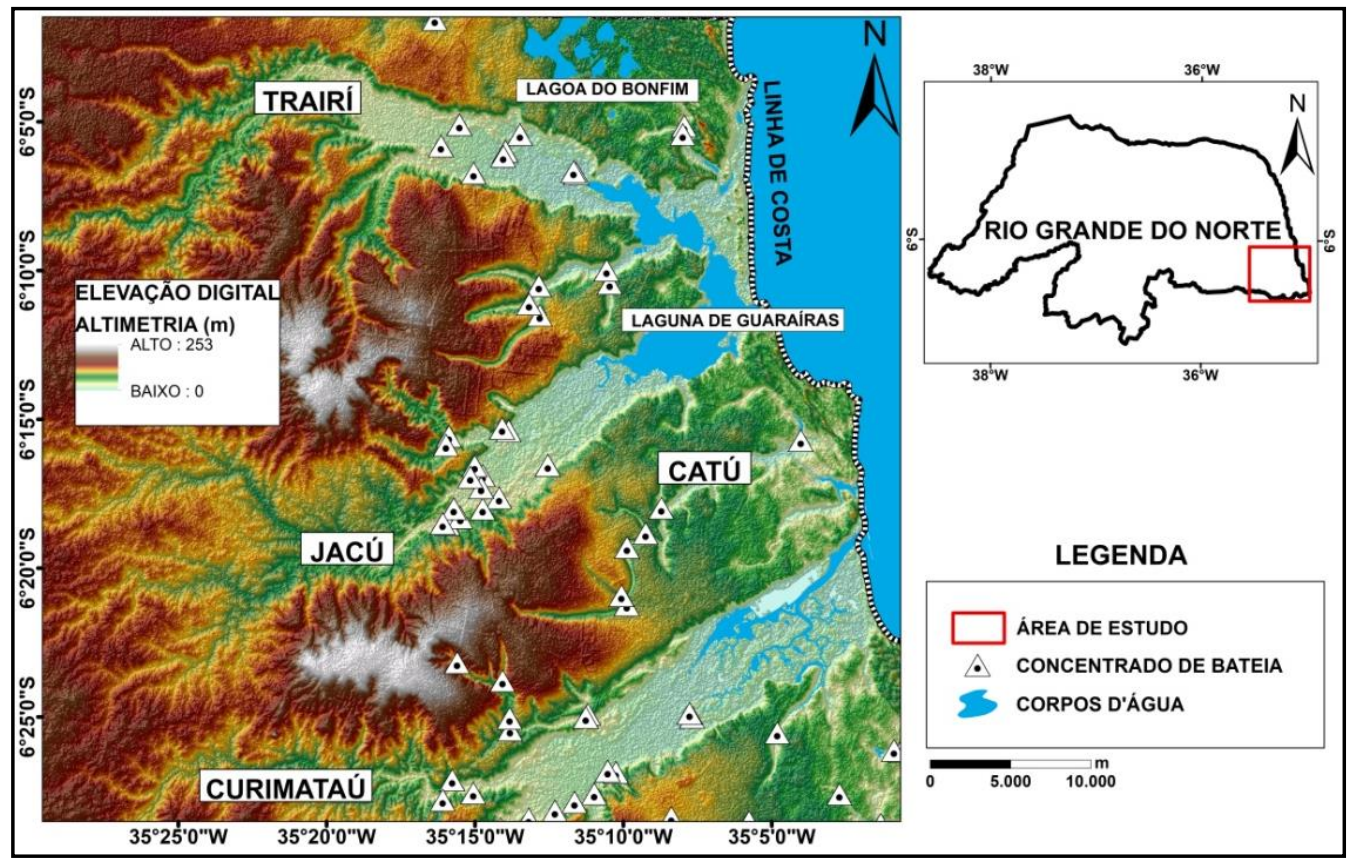

Figura 1 - Mapa de localização da área de estudo e modelo de elevação digital acrescido das ocorrências dos minerais concentrados em bateia e incisões fluviais das bacias hidrográficas presentes na área.

\section{Aspectos geológicos}

A geologia que abrange a folha São José do Mipibu será descrita de acordo com Lima e Dantas (2016), na qual, apresentam em seu contexto geológico unidades litoestratigráficas divididas em mesocenozóicas, neoproterozóicas, paleoproterozóicas e a arqueanas.

As rochas que constituem as unidades mesocenozóicas são, predominantemente, arenitos e conglomerados do Grupo Barreiras, rochas sedimentares do calcário Tamatunduba e sedimentos incosolidados. Essas unidades litoestratigráficas recobrem aproximadamente $70 \%$, da área mapeada. As unidades neoproterozóicas são caracterizadas pela presença das principais suítes intrusivas da região, variando entre biotitamonzogranitos, monzogranitos a sienogranitos porfiríticos e dioritos, quartzo-dioritos, quartzo-monzonitos com variadas formas e dimensões. A unidade paleoproterozóica é composta pelo Complexo SerrinhaPedro Velho, sendo composto por rochas variando entre biotita-hornblenda ortognaisses monzograníticos a granodioríticos bandados com lentes de calcissilicáticas, biotita-hornblenda ortognaisses granodioríticos a tonalito bandado, hornblenda-biotita ortognaisses granodioríticos a tonalito migmatizados e augen gnaisses graníticos, hornblenda-ortognaisses monzogranítico, ortognaisses bandado, biotita-ortognaisses. As unidades arqueanas compostas na área são caracterizadas por anfibolitos, piroxênitos e diopsídio-piroxênitos, hornblenda-biotita ortognaisses granodioríticos a graníticos e migmatitos bandados e biotita-hornblenda augen gnaisse.

Segundo Maia e Bezerra (2011) a área estudada apresenta variações eustáticas e climáticas, nas quais, contribuem fortemente para a deposição de sedimentos continentais do Grupo Barreiras, delineando a unidade geomorfológica Tabuleiros Costeiros e os vales fluviais que incide na área, seguindo um trend NE-SW no litoral Norte e E-W no litoral sul.

\section{Resultados}

Comumente, $U$ e Th possuem semelhanças químicas entre alguns elementos, como: zircônio $(\mathrm{Zr})$, háfnio $(\mathrm{Hf})$, ítrio (Y), cério (Ce) e outros lantanídeos (Boyle, 1982). Desta forma, a substituição ocasionada por $U$ e Th nos minerais zirconita $\left[\mathrm{Zr}(\mathrm{U}, \mathrm{Th}) \mathrm{SiO}_{4}\right]$ e monazita [Ce (Ce, La, $\mathrm{Nd}$, Th, U, Y) $\mathrm{PO}_{4}$ ] podem ocasionar aumento significativo na radiação captada pelo método nos depósitos placeres. Devido à detecção dos radioelementos ocorrer a baixas profundidades, em torno de $50 \mathrm{~cm}$, sem perder sua resolução a aplicação deste método se torna eficaz em sedimentos inconsolidados de exposição supergênica IAEA (1979). 
Grosz (1983) menciona a importância da distinção das concentrações de minerais pesados a partir dos dados radiométricos de $U$, Th e $K$. Sendo Th e, subordinadamente $U$, de maior relevância devida suas altas concentrações nos minerais estudados, fornecendo assim melhores interpretações na localização de depósitos placeres.
A tabela 1 demonstra os resultados baseados em medições gamaespectométricas laboratoriais. Com isso, a rocha sã irá apresentar valores menores para os elementos captados no método, em contraste, solos gerados por estas mesmas rochas irão concentrar estes elementos, apresentando assim, anomalias mais significativas (Dickson \& Scott, 1997).

Tabela 1 - Concentração de radioelementos em alguns tipos de rochas e solos da Austrália.

\begin{tabular}{|c|c|c|c|c|c|c|}
\hline \multirow{2}{*}{ Tipos de rochas } & \multicolumn{3}{|c|}{ Rochas } & \multicolumn{3}{c|}{ Solos } \\
\cline { 2 - 7 } & $\mathrm{K}(\%)$ & $\mathrm{eU}(\mathrm{ppm})$ & $\mathrm{eTh}(\mathrm{ppm})$ & $\mathrm{K}(\%)$ & $\mathrm{eU}(\mathrm{ppm})$ & $\mathrm{eTh}(\mathrm{ppm})$ \\
\hline Granitóides & $0.3-4.5(2.4)$ & $0.4-7.8(8.3)$ & $2.3-45(16)$ & $0.4-3.9(2.1)$ & $0.5-7.8(2.7)$ & $2-37(13)$ \\
\hline Gnaisses & $2.4-3.8(2.4)$ & $2.1-3.6(2.5)$ & $18-55(15)$ & $0.7-1.9(1.3)$ & $1.6-3.8(2.2)$ & $6-19(12)$ \\
\hline Pegmatitos & $2.6-5.5(3.7)$ & $0.3-1(0.7)$ & $0.3-9.6(2)$ & - & - & - \\
\hline Aplitos & $0.6-4(2.4)$ & $1-8(3.3)$ & $3-20(2)$ & - & - & - \\
\hline Intrusivas intermediarias & $0.7-5.6(2.7)$ & $0.1-1.2(0.8)$ & $0.8-6.1(2.4)$ & $0.7-3.4(1.6)$ & $1.5-2.3(1.9)$ & $2.9-8.4(5.6)$ \\
\hline Intrusivas máficas & $0.1-0.8(0.4)$ & $0.0-1.1(0.3)$ & $0.0-3.1(1.2)$ & - & - & - \\
\hline Ardósias & $0.1-4.0(2.6)$ & $1.6-3.8(2.6)$ & $10-55(19)$ & $0.7-3.0(1.5)$ & $1.2-5(2.3)$ & $6-19(13)$ \\
\hline Arenitos & $0.0-5.5(1.8)$ & $0.7-5.1(2.3)$ & $4-22(12)$ & $0.1-2.4(1.3)$ & $1.2-4.4(2.1)$ & $7-18(11)$ \\
\hline Carbonatos & $0.0-0.5(0.2)$ & $0.4-2.9(1.6)$ & $0-2.9(1.4)$ & - & - & - \\
\hline
\end{tabular}

Fonte: Silva, 2010 (modificado de Dickson \& Scott, 1997).

Partindo do principio proposto pela IAEA (1979) e Dickson \& Scott (1997), anomalias encontradas em solos gerados "in situ" são reflexo da radiação proveniente da rocha sã, foram interpretadas anomalias nos depósitos e rochas sedimentares mesocenozóicas presentes nas drenagens das bacias hidrográficas dos rios Trairí, Jacú, Catú e Curimataú.

\section{Tório (Th)}

Primeiramente, foram analisadas as drenagens referentes as bacias dos rios Trairí, Jacú e Catú na porção central e norte do mapa eTH (Fig. 2). Os picos de anomalias variam de 4,4 a 22,9 ppm (médios) possuindo também valores de 0,0 a $3,9 \mathrm{ppm}$ (baixos), de menor expressão. Comparando as rochas e solos presentes na tabela $1 \mathrm{com}$ a geologia da área, as anomalias podem ser associadas a arenitos, carbonatos e seus respectivos solos. Vale ressaltar a importância das rochas intrusivas e metamórficas presentes na região como possível fonte de sedimentos nos vales fluviais.

As anomalias baixas podem remeter a atenuação da radiação gama causada pela densa vegetação e região inundada ou corpos d'água aflorantes (IAEA, 1979). Os picos médios delineiam-se nas drenagens (Fig. 2A, B, C e D) e evidenciam a associação destes valores anômalos a radioelementos captados nas incisões fluviais das bacias hidrográficas. A bacia hidrográfica do rio Curimataú, localizada na porção sul do mapa eTH (Fig. $2 \mathrm{C}$ e D) apresenta picos variando aproximadamente de 22,9 a >38,1 ppm (altos), médios e baixos. Em comparação com a tabela 1 é possível notar a semelhança com as demais bacias, mas, é necessário ressaltar a presença de anomalias altas que inferem a presença de concentrações similares de eTh as de gnaisses e granitóides em depósitos e rochas sedimentares associados ao vale deste rio e seus afluentes, ainda é possível identificar anomalias médias a altas paralelas a linha de costa, podendo ser inferidas dentro dos depósitos litorâneos. Desta forma é possível supor a origem destes minerais pesados como sendo fruto da dissecação das diversas rochas presentes na área, mas como a amostragem da Folha São José do Mipibu se limitou a região próxima a foz, não é possível estimar com exatidão a sua origem.

\section{Urânio (U)}

No mapa do Elemento $U$ (Fig. 3), as drenagens associadas às bacias hidrográficas da área de estudo, apresentam teores variando aproximadamente de 0,0 a 2,2 (ppm) em seus canais principais e afluentes, sendo a atenuação da radiação também evidenciada no mapa. A comparação com a tabela 1 demonstrou uma ampla distribuição da radiação gama produzida, não sendo possível o uso como determinante na localização de depósitos.

É possível ressaltar as bacias referentes aos rios Trairí, Jacú e Catú como sendo responsáveis por uma distribuição semi-homogênea das anomalias (Fig. 3a e 2b) e com a atenuação notada na Lagoa do Bonfim e laguna de Guaraíras, contrastando apenas com anomalias próximas a foz, delineadas nas drenagens destes rios e anomalias paralelas a linha de costa. As anomalias se destacam na bacia hidrográfica do rio Curimataú, a qual, possui picos de anomalias de até 4,1 ppm no seu leito. A atenuação também é notada próxima à foz, mas a concentração de picos anômalos em regiões de confluência entre vale principal e drenagens afluentes (Fig. 3D) e em seu vale principal (Fig. 3C) ressaltam a possível contribuição de radiação gama proveniente de minerais presentes em placeres. 


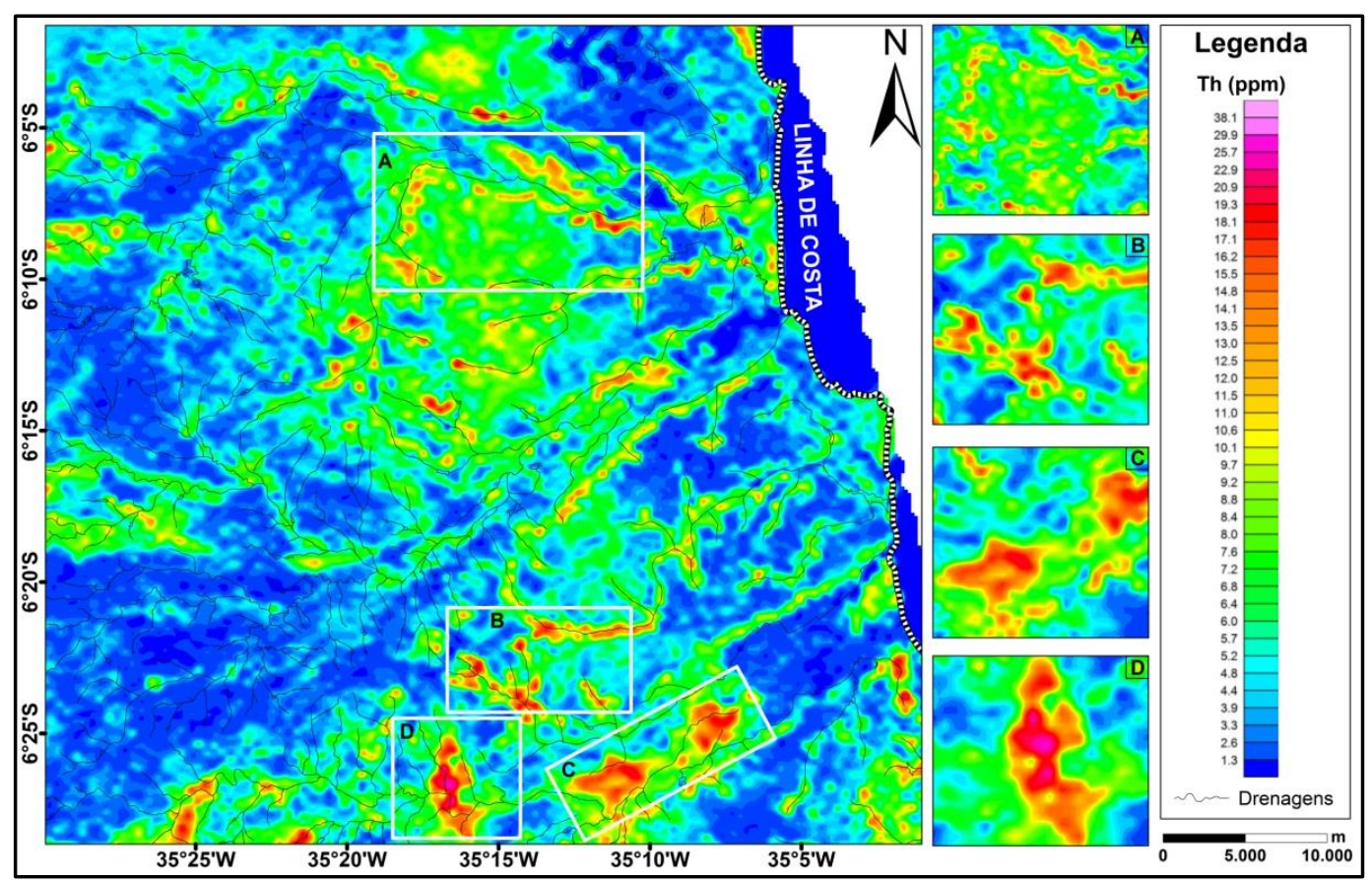

Figura 2 - Mapa das concentrações do elemento Th (eTh). A) região anômala predominantemente média com picos baixos dentro do vale principal da bacia do rio Trairí e seu afluente, B) Porção centro-oeste do polígono demonstra anomalias médias delineadas na incisão fluvial do rio Catú e a porção centro sul evidencia anomalias médias em drenagens afluentes ao canal principal do rio Curimataú, C) Anomalia média distribuida no canal principal do rio Curimataú e D) Região anômala alta a média na zona de confluência entre afluentes e canal principal do rio Curimataú.

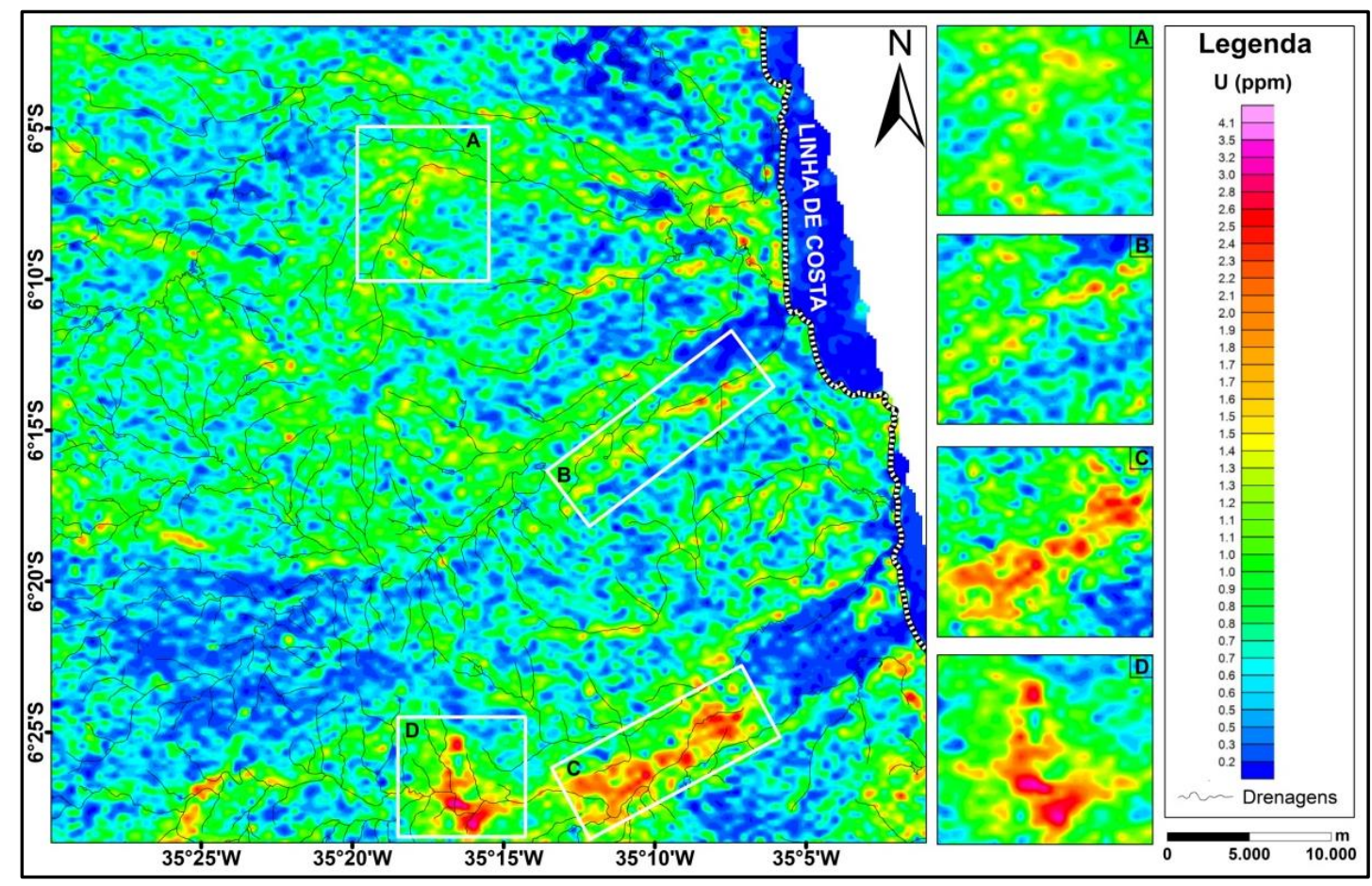

Figura 3 - Mapa das concentrações do elemento $U(\mathrm{eU})$. A) região anômala média a baixa dentro do vale principal da bacia do rio Trairí e seu afluente, B) Anomalia média a baixa presente na margem direita do vale do rio Jacú e seu afluente, C) Anomalia Média a baixa distribuída no vale do canal principal do rio Curimataú e D) anômala alta (extremo norte) e média a baixa na zona de confluência entre afluentes e canal principal do rio Curimataú. 


\section{Conclusão}

A partir dos dados apresentados e correlacionados é possível inferir a existência regiões prospectivas para minerais pesados na área de estudo, corroborando assim, a ideia apresentada por Grosz (1983) de que o bom funcionamento dos instrumentos na obtenção dos dados e uma boa resolução atrelada a uma boa concentração e exposição dos sedimentos garantirão ótimos resultados e baixa atenuação da radiação devido ao "overburden".

A análise das bacias hidrográficas evidenciou a maior concentração de anomalias elevadas na porção sul da área de estudo, podendo então remeter a placeres zircomonazíticos associados aos vales fluviais e incisões afluentes a bacia do rio Curimataú. Ocorrem anomalias de menores valores e expressão nas bacias hidrográficas dos rios Trairí, Jacú e Catú na porção centro e norte da área, evidenciando assim a possível diminuição da concentração dos minerais zircão e monazita nestas bacias hidrográficas, mas não necessariamente reduz 0 potencial exploratório destas regiões.

Desta forma, é possível notar as zonas de maior interesse prospectivo atreladas a regiões de confluência e vales fluviais dos principais canais, apresentando picos anômalos mínimos de $T h>10$ ppm e $U>1,4$ e máximos chegando a $>38,1 \mathrm{ppm}$ de Th e $>4,1 \mathrm{ppm}$ de $U$, sendo ressaltados nos mapas de eTh e eU (Fig. 2a,b, c e d e 3a,b,c e d).

O método aeroradiométrico como ferramenta de prospecção mineral em rochas sedimentares e sedimentos, ainda que não seja comumente utilizado, demonstrou resultados positivos em relação ao ambiente geológico aplicado. A ambiguidade foi reduzida quando realizada a integração com os dados geoquímicos de concentrado de bateia, podendo assim, ser considerada uma ferramenta indispensável na localização de depósitos placeres zirco-monazíticos.

\section{Agradecimentos}

- Diretoria Acadêmica de Recursos Naturais (DIAREN) do Instituto Federal de Ciência, Educação e Tecnologia do Rio Grande do Norte (IFRN);

- Departamento de Geofísica (DGEF) da Universidade Federal do Rio Grande do Norte (UFRN);

- Departamento de Geologia (DGEO) da Universidade Federal do Rio Grande do Norte (UFRN).

\section{Referências}

ADDAD, João Eduardo. Minerais Pesados: uma ferramenta para prospecção, proveniência, paleogeografia e análise ambiental. 2. ed. São Paulo: Imprensa Universitária, 2010.

BOYLE RW. 1982. Geochemical prospecting for uranium and thorium deposits. Amsterdam, Elsevier. $498 \mathrm{p}$.

Dickson, Bruce \& M. Scott, K. 1997. Interpretation of aerial gamma-ray surveys - adding the geochemical factors. AGSO journal of Australian geology \& geophysics. 17. 187-199.
Grosz, E. Andrew. (1983). APPLICATION OF TOTALCOUNT AERORADIOMETRIC MAPS TO THE EXPLORATION FOR HEAVY-MINERAL DEPOSITS IN THE COASTAL PLAIN OF VIRGINIA. US Geological Survey Prof. Paper 1263. 23p.

INTERNATIONAL ATOMIC ENERGY AGENCY, Gamma ray Surveys in Uranium Exploration, Technical Reports Series No. 186, IAEA, Vienna (1978).

LIMA, Maria da Guia; DANTAS, Eugênio Pacelli. GEOLOGIA E RECURSOS MINERAIS DA FOLHA SÃO JOSÉ DE MIPIBU SB.25-A-Y-II e III. Recife: CPRM, 2016.

MAIA, Rúbson Pinheiro; BEZERRA, Francisco Hilário Rego. GEOMORFOLOGIA DO NORDESTE: CONCEPÇÕES CLÁSSICAS E ATUAIS ACERCA DAS SUPERFÍCIES DE APLAINAMENTO NORDESTINAS. Revista de Geografia, Recife, n. 1, p.1-14, 2010.

OLIVA, Luiz Antônio. Métodos e Técnicas de Pesquisa Mineral. Brasília: DNPM, 1985. 355 p.

SILVA, Sebastião Milton P. da et al. Identificação gamaespectrométrica de placeres rutilo-monazíticos neoproterozóicos no sul da Faixa Seridó, nordeste do Brasil. Rev. Bras. Geof. 2010, vol.28, n.1

SOUZA, Jocelyn Lopes de. ANOMALIAS
AEROGAMAESPECTROMÉTRICAS (K, eU e eTh) DA
QUADRÍCULA DE ARARAS (SP) E SUAS RELAÇÕES
COM PROCESSOS PEDOGENÉTICOS E
FERTILIZANTES FOSFATADOS. RBGf, Rio de Janeiro,
v. 23, n. 3, p.251-274, out. 2005.
v. 23, n. 3, p.251-274, out. 2005. 